\title{
Incentive reduction: Increases in postreinforcement detention and subsequent responding'
}

\author{
JAMES H. McHOSE and LARRY L. JACOBY, Southern \\ Illinois University, Carbondale, Ill. 62901
}

Three groups of 10 rats each received 64 acquisition and 64 postshift trials in an L-shaped double-alley apparatus. In the postshift period two groups received test trials on which the postreinforcement detention time in the first goalbox (G1) was increased. For one of these groups this increase occurred simultaneously with a reduction in GI reward magnitude. The results indicated that for neither group did postreinforcement detention increase elevate second-alley speeds relative to those of a group which always received the longer postreinforcement detention.

In recent years considerable attention has been focused on the effects of various types of incentive reduction (IR) on responses immediately following the IR. The resultant literature indicates that the speed with which a rat traverses the second alley (A2) of a double-alley apparatus is enhanced by some, but not all, types of IR in the first goal box (G1). Thus omission of reward on occasional test trials in G1 elevates A2 speeds compared to those of a control group which never receives reward in Gl (Wagner, 1959; Barrett et al, 1965). An incomplete reward reduction, to some nonzero magnitude, however, does not appear to facilitate performance in A2 (Barrett et al, 1965; Daly, 1968), nor does an increase in delay of reinforcement (McHose, 1966a). Finally, recent evidence suggests that an incomplete reduction in reward magnitude, when accompanied by an increase in delay of reinforcement, does facilitate A2 speeds (McHose, 1966b; 1968). In studies which manipulated delay of reinforcement, Ss were trained on a short delay of reinforcement in Gl and subsequently administered long-delay test trials. In these studies an increase in delay of reinforcement is confounded with an increase in the total detention time in G1. The present experiment, concerned with whether effects previously attributed to prereinforcement delay manipulations might, in fact, reflect the effects of other temporal parameters of detention in $\mathrm{Gl}$, manipulated postreinforcement detention in $\mathrm{Gl}$ in a fashion analogous to previous prereinforcement delay manipulations.

\section{METHOD}

Thirty male albino rats received 64 acquisition and 64 postshift trials in an L-shaped double-alley apparatus identical to that employed previously (McHose, 1966a). Briefly, the apparatus consisted of a first start, run and goal section, and a second run and goal section. The first goal box (G1) served as the start box for the second alley (A2).

Thirteen days prior to the first training day Ss were placed on a 23-h food-deprivation cycle maintained throughout the experiment. On the two days immediately preceding the first training day Ss received approximately $1 \mathrm{~g}$ of $45-\mathrm{mg}$ Noyes pellets, identical with the subsequent reward pellet, prior to their daily ration. On these days Ss were also allowed to explore the first start and nun sections of the apparatus. Ss received two trials per day on the first two training days and four trials per day thereafter.

Three groups of $10 \mathrm{Ss}$ each were designated according to the reinforcement condition (number of pelletspostreinforcement detention) received in $G 1$ on each acquisition trial: Groups $1-0,8-0$, and 1-15. During the postshift period conditions for Group 1-15 were unchanged, while Groups $1-0$ and $8-0$ received test trials of one pellet followed by $15-\sec$ detention in Gl (1-15) on $50 \%$ of their trials and their respective reinforcement conditions in $G 1$ on the remaining $50 \%$ of the trials according to the following repeating cycle of test $(\mathrm{T})$ and acquisition (A) trials: ATAT, TAAT, TATA, ATTA. On nondetention trials the start door separating G1 from $A 2$ was opened after $S$ had eaten and maintained an orientation toward the door for $3 \mathrm{sec}$. On detention trials, the detention cycle began as $S$ consumed the pellet and a 3-sec orientation was required at the end of the cycle before the second start door was opened. All Ss always received two pellets immediate reinforcement in the second goal box.

Running latencies over a 1 -ft section of $A 2$ beginning 6 in. from $\mathrm{G} 1$ were reciprocated yielding $A 2$ running speeds.

\section{RESULTS}

Group mean A2 running speeds are plotted as a function of blocks of eight trials in Fig. 1. The vertical line at Block 8 indicates the point at which test trials were initiated for Groups $1-0$ and $8-0$. For Groups $1-0$ and $8-0$, postshift mean A2 speeds following test (1-15) and standard (1-0 and $8-0$, respectively) $G 1$ reinforcement conditions are plotted separately.

Looking first at the preshift data, it may be seen that speeds of Group 1-0 stabilized at a higher level than did those of Group 8-0, but at a lower level than those of Group 1-15. Variance analysis of these data over Blocks 6-8 yielded a significant $(\mathrm{p}<.01)$ Groups effect, $\mathrm{F}=11.41, \mathrm{df}=2 / 27$. Tukey (A) comparisons (cf. Winer, 1962) indicated that each group differed significantly from the other two.

Of primary interest in the present study was the effect of an increase in postreinforcement detention during the postshift period. Inspection of Fig. 1 indicates that the performance of Groups $1-0$ and $8-0$ on 1-15 trials eventually stabilized at approximately the same level, a speed level slightly below that of Groups 1-15. Variance analysis of the data for the three groups on 1-15 trials over Blocks 14-16 yielded a nonsignificant Groups effect $(F=2.19, \mathrm{df}=2 / 27)$.

\section{DISCUSSION}

In the present study increasing postreinforcement detention in G1 did not elevate the speeds of either Groups 8-0 or 1-0 above those of a control condition, Group 1-15. The present data thus afford no evidence that an increase, per se, in G1 postreinforcement detention enhances $A 2$ performance regardless of whether such an increase is accompanied by a decrease in reward magnitude (Group 8-0) or not (Group 1-0). Since

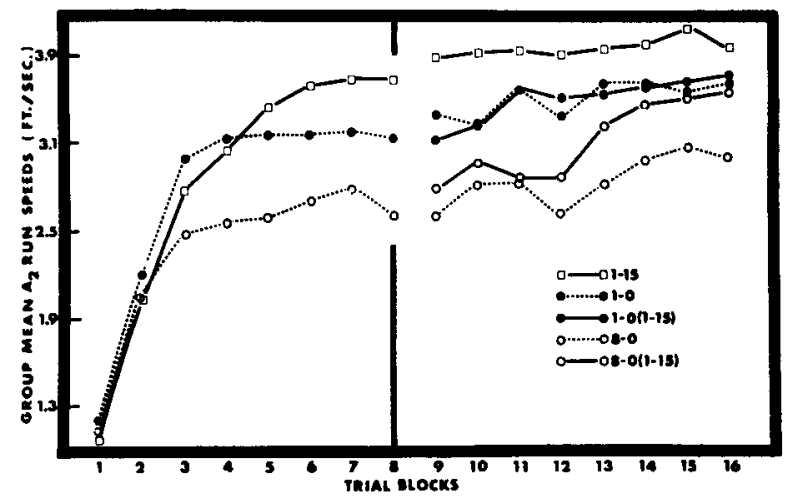

Fig. 1. Pre- and postshift A2 speeds as a function of blocks of trials. 
the effects of increasing postreinforcement delay in G1 simultaneous with an incomplete reduction of reward in the present study are in a direction opposite to the effects of simultaneous prereinforcement delay increase and reward reduction, consideration of total detention time becomes superfluous, its only possible descriptive use being the ordering of cell means in a pre- by postreinforcement increase factorial study. In view of the present results, then, it would appear that previous demonstrations of enhanced performance following simultaneous increases in prereinforcement delay and decreases in reward magnitude (McHose, 1966b, 1968) reflect the effects of increased prereinforcement delay rather than increases in total detention time in G1.

\section{REFERENCES}

BARRETT, R. J., PEYSER, C. S., \& McHOSE, J. H. Effects of complete and incomplete reward reduction on a subsequent response. Psychonomic Science, 1965, 3, 277-278.
DALY, H. B. Excitatory and inhibitory effects of complete and incomplete reward reduction in the double runway. Journal of Experimental Psychology, 1968, 76, 430-438.

McHOSE, J. H. Incentive reduction: Delay increase and subsequent responding. Psychonomic Science, 1966a, 5, 213-214.

McHOSE, J. H. Incentive reduction: Simultaneous delay increase and magnitude reduction and subsequent responding. Psychonomic Science, 1966b, 5, 215-216.

McHOSE, J. H. Incentive reduction: Varied simultaneous reductions and subsequent responding. Psychonomic Science, 1968, 11, 313-314.

WAGNER, A. R. The role of reinforcement and non-reinforcement in an "apparent frustration effects." Journal of Experimental Psychology, $1959,57,130-136$.

WINER, B. Statistical principles in experimental design. New York: McGraw-Hill, 1962.

NOTE

1. Supported by Research Grants MH-10340 and Training Grant MH-07817 from the United States Public Health Service.

\section{(Continued from page 31)}

confirmed the apparent effects, showing significant effects for a linear decline in proportion of possible reinforcements obtained as a function of time on task $(F=17.50, \mathrm{df}=1 / 3$, $p<.05)$ and a significant difference between $\mathrm{Ss}(\mathrm{F}=52.02$, df $=1 / 3, p<.01$ ). The decrement resembles that found in human Ss in vigilance situations and supports Holland's suggestion that signal detections parallel conventional reinforcers.

The other significant main effect, that for Ss, can be seen (Fig. 2) to be associated with a difference in the response rates of the two Ss. Analysis of variance of number of responses showed significant effects for $\mathrm{Ss}(\mathrm{F}=86.17, \mathrm{df}=1 / 3, \mathrm{p}<.01)$ and for an interaction between $S s$ and time on task $(F=4.72$, $\mathrm{df}=3 / 160, \mathrm{p}<.01$ ). Fig. 3 shows the effect of adjusting by analysis of covariance the number of reinforcements obtained while holding constant the number of responses. When this is done, $S 1$ shows a decreasing efficiency of performance and S4 an increasing efficiency, with this interaction being the only significant effect $(\mathrm{F}=4.20, \mathrm{df}=1 / 159, \mathrm{p}<.01)$. Thus, the decline in response rate shown by $\mathrm{S} 4$ is sufficient to offset this gain in efficiency, resulting in the overall decline in number of reinforcements shown in Fig. 1. This suggests that there may be two mechanisms at work, each capable of producing a diminution in number of reinforcements obtained as a function of time on task. Both a reduction in response rate

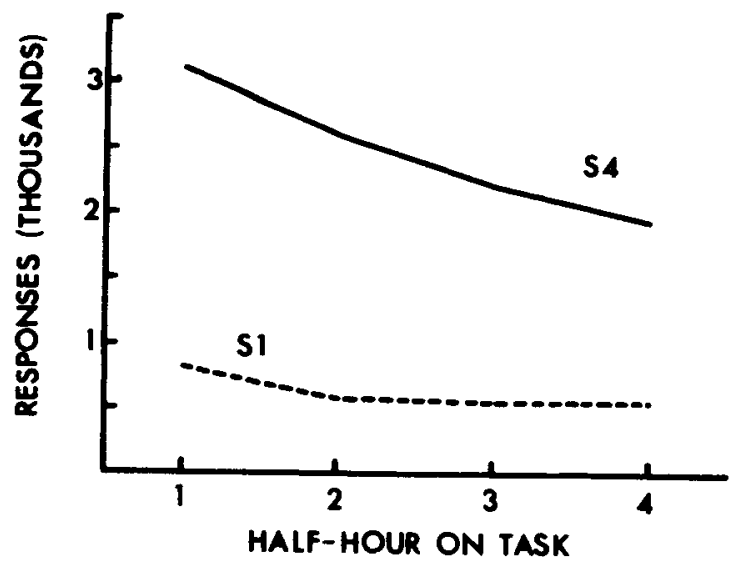

Fig. 2. Response rate as a function of time on task.

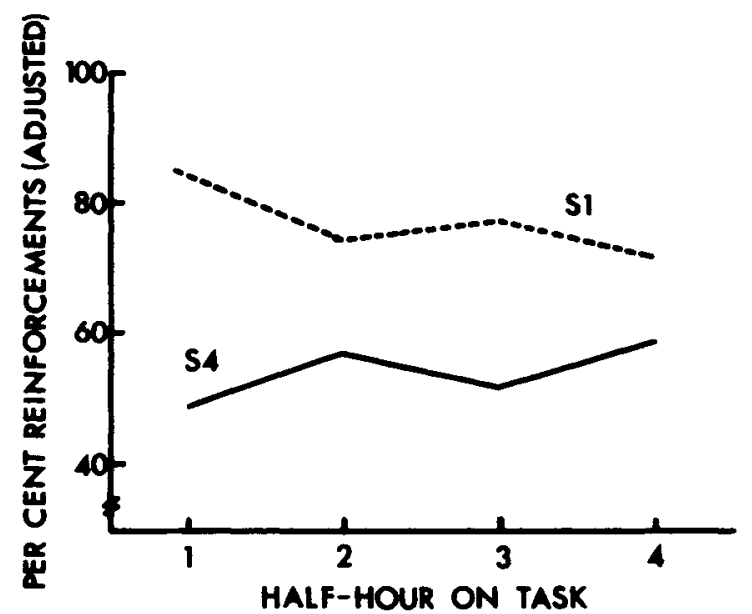

Fig. 3. Per cent of possible reinforcements obtained, adjusted for number of responses, as a function of time on task.

and a rise in the proportion of responses emitted during the extinction component would tend to decrease the probability that a response would coincide with the brief period of the limited hold. The availability of different response strategies to $S$ would by itself be sufficient to account for the consistently reported individual differences in vigilance performance. This suggests the possibility of improving detection performance by training procedures specifically designed to alter the observing rate.

\section{REFERENCES}

FERSTER, C. B., \& SKINNER, B. F. Schedules of reinforcement. New York: Appleton-Century-Crofts, 1957.

HOLLAND, J. G. Technique for behavioral analysis of human observing. Science, 1957, 125, 348-350.

HOLLAND, J. G. Human vigilance. Science, 1958, 128, 61-67.

MACKWORTH, N. H. Researches on the measurement of human performance. Medical Research Council Special Report Series, No. 268. London: HMSO, 1950.

WYCKOFF, L. B. The role of observing responses in discrimination learning. Part 1. Psychological Review, 1952, 59, 431-442. 